\title{
PERFORMANCE DEMONSTRATION PROGRAM PLAN FOR ANALYSIS OF SIMULATED HEADSPACE GASES
}

\author{
Revision 6
}

November 2007

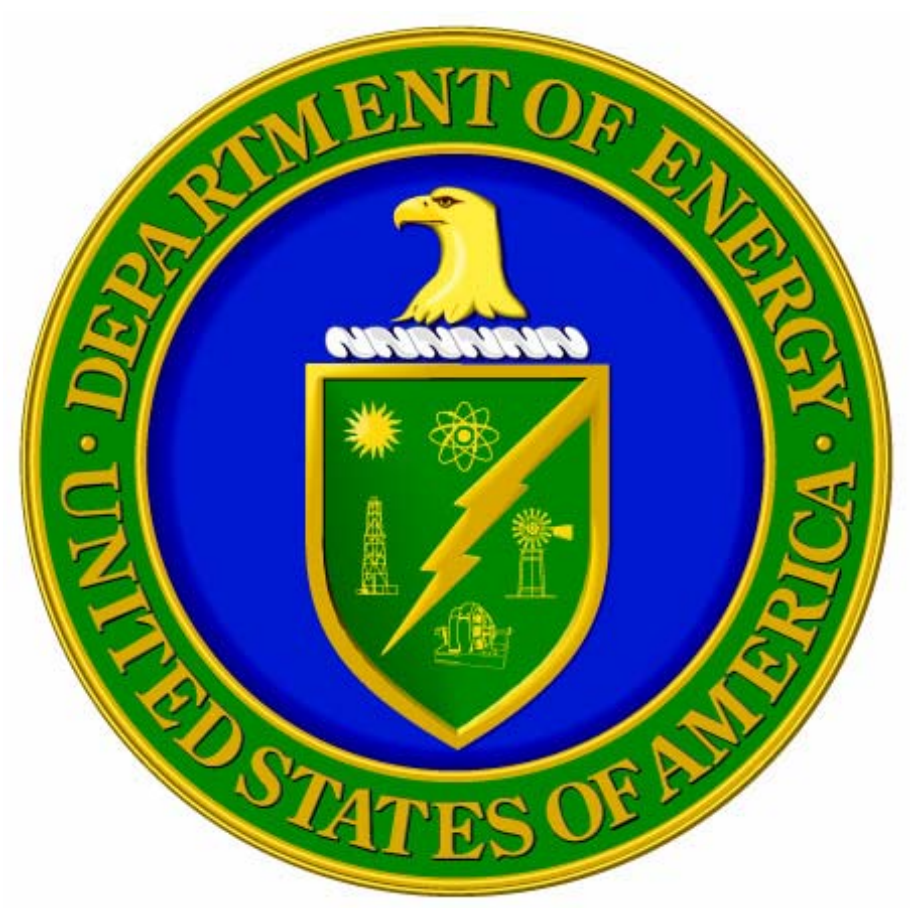

U.S. Department of Energy

Carlsbad Field Office

Office of the National TRU Program

This document supersedes revision 5 of DOE/CBFO-95-1076 
This document as been submitted as required to:

Office of Scientific and Technical Information

PO Box 62

Oak Ridge, TN 37831

(615) 576-8401

Additional information about this document may be obtained by calling 1-800-336-9477. Copies may be obtained by contacting the National Technical Information Service, U.S. Department of Commerce, 5285 Port Royal Road, Springfield, VA 22101. 


\section{Performance Demonstration Program Plan for Analysis of Simulated Headspace Gases}

\section{DOE/CBFO-95-1076 \\ Revision 6}

November 2007 $\begin{array}{ll}\text { Approved By: } & \text { //signature on file// } \\ & \text { Office Director } \\ & \text { Office of the National TRU Program }\end{array}$

Concurred By: //signature on file// Quality Assurance Manager

$\begin{array}{ll}\text { Prepared By: } & \text { //signature on file// } \\ & \text { PDP Appointee } \\ & \text { Office of the National TRU Program }\end{array}$
Date: $\underline{11 / 13 / 2007}$

Date: $\underline{11 / 13 / 2007}$ 


\section{TABLE OF CONTENTS}

ACRONYMS ....

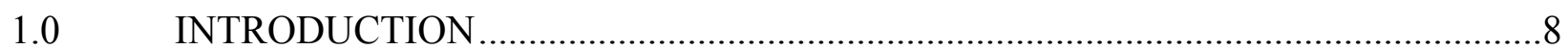

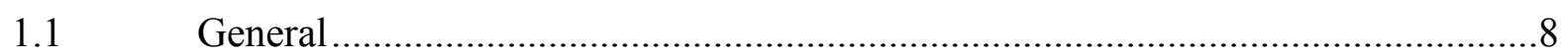

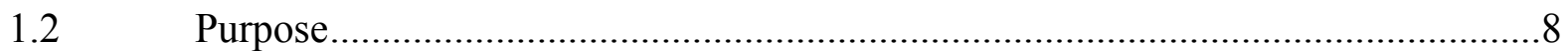

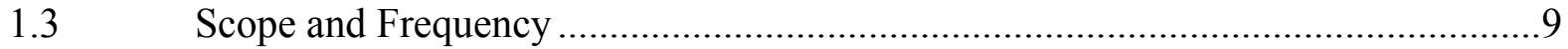

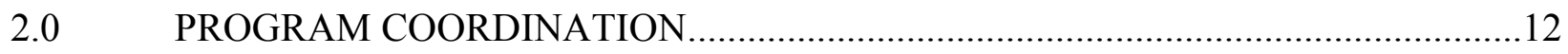

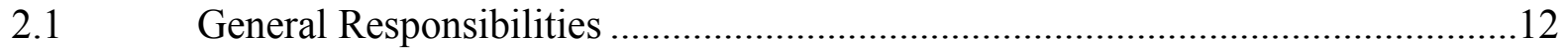

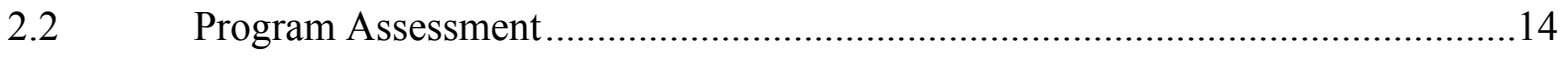

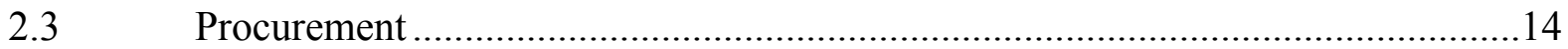

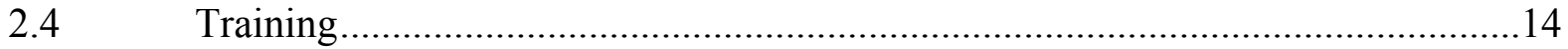

3.0 PREPARATION AND DISTRIBUTION OF PDP SAMPLES …….........................16

4.0 ANALYTICAL AND DATA REPORTING REQUIREMENTS …….......................18

4.1 Sample Receipt and Chain of Custody ……..................................................18

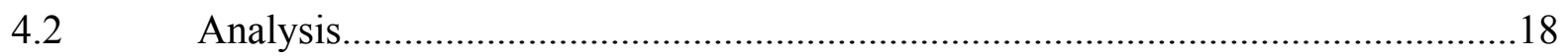

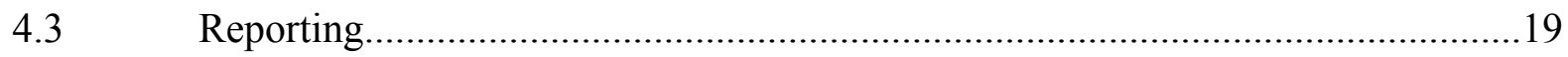

4.3.1 Report Contents ................................................................................. 19

4.3.2 Canister Management .......................................................................... 20

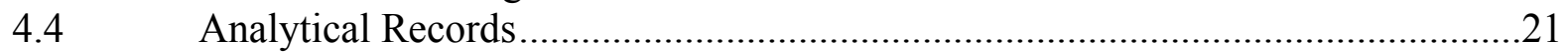

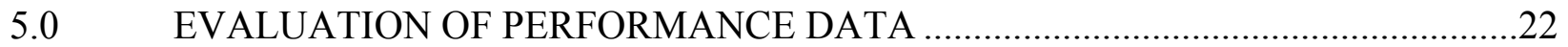

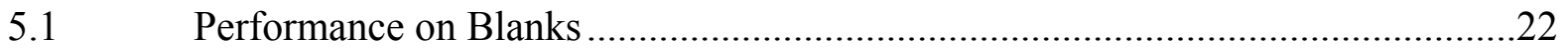

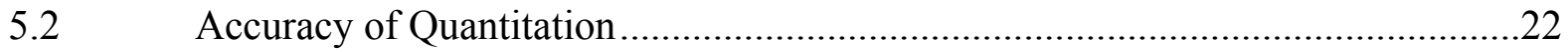

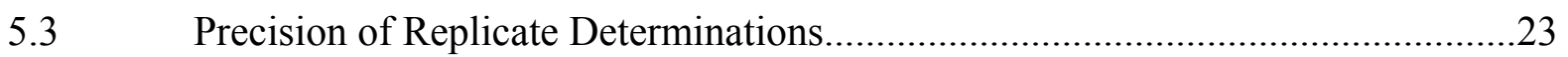

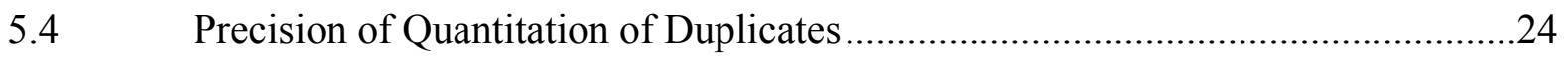

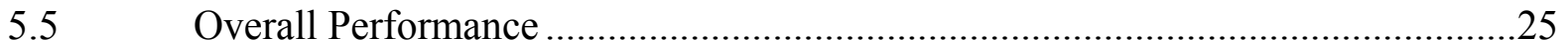

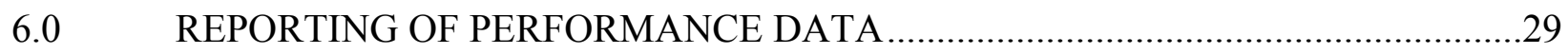

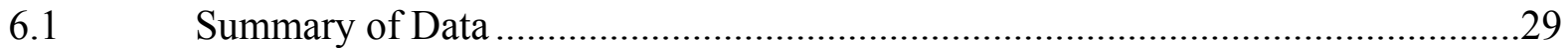

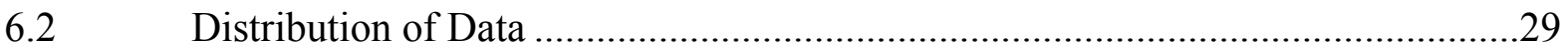

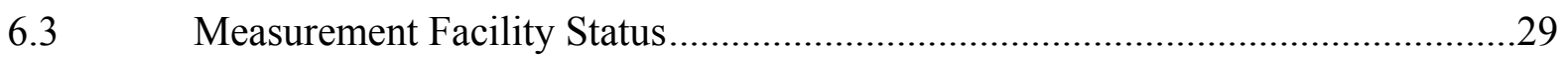

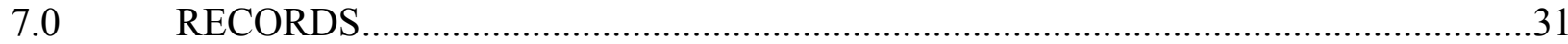

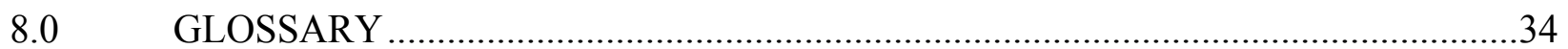

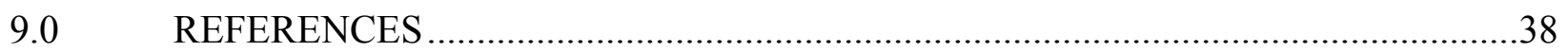

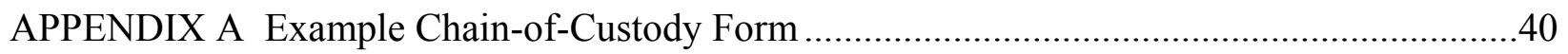

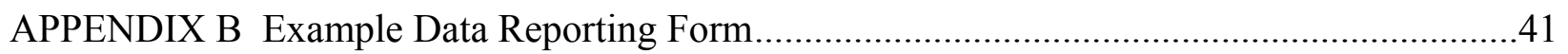

APPENDIX C Criteria for Identical Analytical Systems for the Headspace Gas PDP ................43 


\section{LIST OF TABLES}

Table 1 VOC Headspace Target Compound List and Program Required Quantitation Limits....11

Table 2 Blind Audit Sample Concentration Ranges by Class ..................................................16

Table 3. Headspace Gas PDP Documentation/Records List ..................................................31

\section{LIST OF FIGURES}

Figure 1 Organization and Information for the HSG PDP 


\section{ACRONYMS}

\begin{tabular}{|c|c|}
\hline$\% \mathbf{R}$ & percent recovery \\
\hline CBFO & Carlsbad Field Office \\
\hline COC & chain of custody \\
\hline CTC & critical target compound \\
\hline DOE & Department of Energy \\
\hline FTIRS & Fourier transform infrared spectrometry \\
\hline HSG & headspace gas \\
\hline MDL & method detection limit \\
\hline NDA & nondestructive assay \\
\hline NELAC & National Environmental Laboratory Accreditation Conference \\
\hline NIST & National Institute of Standards and Technology \\
\hline PDP & Performance Demonstration Program \\
\hline ppmv & parts per million by volume \\
\hline PRQL & program required quantitation limit \\
\hline QA & quality assurance \\
\hline QAO & quality assurance objective \\
\hline QAPD & Quality Assurance Program Document \\
\hline QC & quality control \\
\hline RCRA & Resource Conservation and Recovery Act \\
\hline RPA & relative percent accuracy \\
\hline RPD & relative percent difference \\
\hline RSD & relative standard deviation \\
\hline SPC & sample preparation contractor \\
\hline TC & target compound \\
\hline TIC & tentatively identified compound \\
\hline TRU & transuranic \\
\hline VOC & volatile organic compound \\
\hline VTSR & validated time of sample receipt \\
\hline WAP & Waste Analysis Plan \\
\hline WIPP & Waste Isolation Pilot Plant \\
\hline
\end{tabular}




\section{Significant Changes to the Headspace Gas PDP Plan, Revision 6}

\section{General}

1. The document was updated to reflect the current organizational structure of CBFO. References to the Office of Characterization and Transportation were replaced with Office of National TRU Program.

2. Editorial changes were incorporated as appropriate to improve technical clarity.

3. A number of changes to the document were required to describe the relationship between CTAC and the commercial suppliers of HSG PDP sample preparation contractor (SPC) services and the standard gases used to prepare the HSG PDP samples. Prior to this revision, the HSG PDP SPC was a DOE National Laboratory. 


\subsection{INTRODUCTION}

\subsection{General}

The Performance Demonstration Program (PDP) for headspace gases distributes blind audit samples in a gas matrix for analysis of volatile organic compounds (VOCs). Participating measurement facilities (i.e., fixed laboratories, mobile analysis systems, and on-line analytical systems) are located across the United States. Each sample distribution is termed a PDP cycle. These evaluation cycles provide an objective measure of the reliability of measurements performed for transuranic (TRU) waste characterization.

The primary documents governing the conduct of the PDP are the Quality Assurance Program Document (QAPD) (DOE/CBFO-94-1012) and the Waste Isolation Pilot Plant (WIPP) Waste Analysis Plan (WAP) contained in the Hazardous Waste Facility Permit (NM4890139088TSDF) issued by the New Mexico Environment Department (NMED). The WAP requires participation in the PDP; the PDP must comply with the QAPD and the WAP. This plan implements the general requirements of the QAPD and the applicable requirements of the WAP for the Headspace Gas (HSG) PDP.

Participating measurement facilities analyze blind audit samples of simulated TRU waste package headspace gases according to the criteria set by this PDP Plan. Blind audit samples (hereafter referred to as PDP samples) are used as an independent means to assess each measurement facility's compliance with the WAP quality assurance objectives (QAOs). To the extent possible, the concentrations of VOC analytes in the PDP samples encompass the range of concentrations anticipated in actual TRU waste package headspace gas samples. Analyses of headspace gases are required by the WIPP to demonstrate compliance with regulatory requirements. These analyses must be performed by measurement facilities that have demonstrated acceptable performance in this PDP. These analyses are referred to as WIPP analyses and the TRU waste package headspace gas samples on which they are performed are referred to as WIPP samples in this document. Participating measurement facilities must analyze PDP samples using the same procedures used for routine waste characterization analyses of WIPP samples.

\subsection{Purpose}

The purpose of the HSG PDP is to demonstrate the capability of each participating measurement facility to meet the data quality objectives stated in the WAP for VOC headspace gases. In addition to the HSG PDP described in this document, there are two other elements to the PDP (nondestructive assay and RCRA constituent analysis in solid samples). These elements are described in three other PDP Plans: Performance Demonstration Program Plan for Nondestructive Assay of Drummed Wastes for the TRU Waste Characterization Program (DOE/CBFO-01-1005), Performance Demonstration Program Plan for Nondestructive Assay of Boxed Wastes for the TRU Waste Characterization Program (DOE/CBFO-01-1006), and Performance Demonstration Program Plan for RCRA Constituent Analysis of Solidified Wastes (DOE/CBFO-95-1077). The Carlsbad Field Office (CBFO) uses the PDP as part of the assessment and approval process for the measurement facilities supplying characterization services for TRU waste. The other two parts of this approval process include the evaluation of 
method performance data submitted by the measurement facility and quality assurance (QA) audits.

This HSG PDP Plan describes the detailed elements of the program, including the nature of the test materials and the analyses required. This plan also identifies the criteria used to evaluate measurement facility performance and discusses the responsibilities of the HSG PDP coordinator, the standard gas vendor (SGV), the sample preparation contractor (SPC), and the participating measurement facilities.

The CBFO is responsible for ensuring the implementation of this plan by designating the program coordinator and by providing technical oversight and coordination for the program. The program coordinator will designate the PDP manager, who will coordinate the three elements of the PDP (HSG, RCRA, and NDA analyses). The PDP manager will designate the HSG PDP coordinator, who administers and coordinates HSG PDP functions such as HSG PDP sample component preparation, subcontractor oversight, scheduling, scoring, and generating summary reports.

\subsection{Scope and Frequency}

In accordance with the WAP, all measurement facilities that perform headspace gas analyses of TRU wastes for disposal at WIPP are required to participate in this PDP. Satisfactory performance of PDP analyses is one of several necessary conditions for certification to ship TRU waste to WIPP.

Acceptable performance in this PDP must be demonstrated initially by all participating measurement facilities prior to the analysis of WIPP samples. Subsequently, all participating measurement facilities shall be evaluated annually, as specified in the WAP. The primary cycle for PDP participation will thus be annual (i.e., every 12 months \pm 1 month). In addition to the primary test cycle, the HSG PDP coordinator may, as necessary, schedule a supplemental cycle prior to the next regular annual cycle. Any such supplemental cycle will be scheduled only for the purposes of qualifying new measurement facilities and/or for requalifying a measurement facility (if necessary) that did not pass in the primary cycle. The participating measurement facility(ies) may be required to provide funding for the supplemental cycle.

If a facility is operating two or more identical analytical systems, only one system needs to participate in any given PDP cycle. The site shall rotate participation in consecutive PDP cycles among identical systems. The exception to this is that any individual system must participate in the PDP at least once every three years. Therefore, if a participant has more than three identical systems, PDP analyses must be conducted and the data reported for more than one system during some of the HSG PDP cycles. The HSG PDP coordinator must be informed of the need for sufficient PDP samples when more than one system will be participating in any given cycle. Each manufacturer or owner/operator making a claim of identical systems shall submit a document to the HSG PDP coordinator identifying the systems and addressing each of the criteria used to define identical systems (see appendix $\mathrm{C}$ ). The submittal of identical system documentation is required when data are reported for each HSG PDP cycle and when an identical system is brought on-line between cycles. 
The criteria for acceptable performance are given in Section 5 of this plan. The PDP samples must be analyzed, with the results reduced and validated, using the same methods, processes, and procedures the measurement facility intends to use to analyze WIPP samples. These methods must have been developed and approved within the guidelines established by the WAP. Only the methods actually used in the PDP can be used to support analysis of WIPP samples. The data generated as a result of the performance demonstration indicate the appropriateness of the method used as well as the performance of the measurement facility.

The VOC analytes in a sample are selected from the list in Table 1. Nine of the listed compounds are identified in the WAP as having special significance with respect to hazardous waste characterization. These nine compounds are referred to as critical target compounds (CTCs).

The remaining VOC analytes listed in Table 1 are called target compounds (TCs) and are those that have been identified as potentially present in the WIPP waste in sufficient quantities to be of quantitative interest for assignment of EPA hazardous waste numbers and/or are identified as hazardous constituents included in 40 CFR §261, Appendix VIII. These compounds do not have disposal room average headspace concentration limits. The performance criteria for the CTCs are more stringent than those for the TCs (Section 5).

Additional VOCs, referred to as non-target compounds (NTCs) in the HSG PDP scoring reports, may also be included in the PDP samples at the discretion of the HSG PDP coordinator. When included, NTCs are required to be reported as tentatively identified compounds (TICs). 
Table 1. VOC Headspace Target Compound List and Program Required Quantitation Limits

\begin{tabular}{|c|c|c|c|}
\hline & VOCs & CAS Number & PRQL (ppmv) \\
\hline 1. & Acetone & $67-64-1$ & 100 \\
\hline 2. & Benzene & $71-43-2$ & 10 \\
\hline 3. & Bromoform & $75-25-2$ & 10 \\
\hline 4. & $n$-Butanol & $71-36-3$ & 100 \\
\hline 5. & Carbon tetrachloride $^{\mathrm{a}}$ & $56-23-5$ & 10 \\
\hline 6. & Chlorobenzene $^{\mathrm{a}}$ & $108-90-7$ & 10 \\
\hline 7. & Chloroform ${ }^{\mathrm{a}}$ & $67-66-3$ & 10 \\
\hline 8. & 1,1-Dichloroethane & $75-34-3$ & 10 \\
\hline 9. & 1,2-Dichloroethane ${ }^{a}$ & $107-06-2$ & 10 \\
\hline 10. & 1,1-Dichloroethene ${ }^{\mathrm{a}}$ & $75-35-4$ & 10 \\
\hline 11. & cis-1,2-Dichloroethene & $156-59-2$ & 10 \\
\hline 12. & trans-1,2-Dichloroethene & $156-60-5$ & 10 \\
\hline 13. & Ethyl benzene & $100-41-4$ & $10^{\mathrm{c}}$ \\
\hline 14. & Ethyl ether & $60-29-7$ & 10 \\
\hline 15. & Methanol & $67-56-1$ & 100 \\
\hline 16. & Methylene chloride ${ }^{a}$ & $75-09-2$ & 10 \\
\hline 17. & Methyl ethyl ketone & $78-93-3$ & 100 \\
\hline 18. & Methyl isobutyl ketone & $108-10-1$ & 100 \\
\hline 19. & $1,1,2,2$-Tetrachloroethane ${ }^{a}$ & $79-34-5$ & 10 \\
\hline 20. & Tetrachloroethene & $127-18-4$ & 10 \\
\hline 21. & Toluene $^{\mathrm{a}}$ & $108-88-3$ & 10 \\
\hline 22. & $1,1,1-$ Trichloroethane ${ }^{a}$ & $71-55-6$ & 10 \\
\hline 23. & Trichloroethene & $79-01-6$ & 10 \\
\hline 24. & 1,1,2-Trichloro-1,2,2-trifluoroethane & $76-13-1$ & 10 \\
\hline 25. & $m$-Xylene $\mathrm{b}^{\mathrm{b}}$ & $108-38-3$ & 10 \\
\hline 26. & $o$-Xylene & $95-47-6$ & 10 \\
\hline 27. & $p$-Xylene ${ }^{b}$ & $106-42-3$ & 10 \\
\hline
\end{tabular}

$\mathrm{PRQL}=$ program required quantitation limit; ppmv $=$ parts per million by volume

a Critical target compounds

b These xylene isomers cannot be resolved by gas chromatography/mass spectrometry, one of the analytical methods that may be employed.

c The ethyl benzene PRQL is 20 ppmv for analyses conducted by Fourier transform infrared spectrometry (FTIRS). 


\subsection{PROGRAM COORDINATION}

\subsection{General Responsibilities}

The reviewing and approving authority for this PDP is the CBFO. Programmatic direction and oversight of the PDP are performed by the Office of the National TRU Program PDP appointee, who manages the PDP on behalf of the CBFO. Figure 1 summarizes the organizational flow of the PDP.

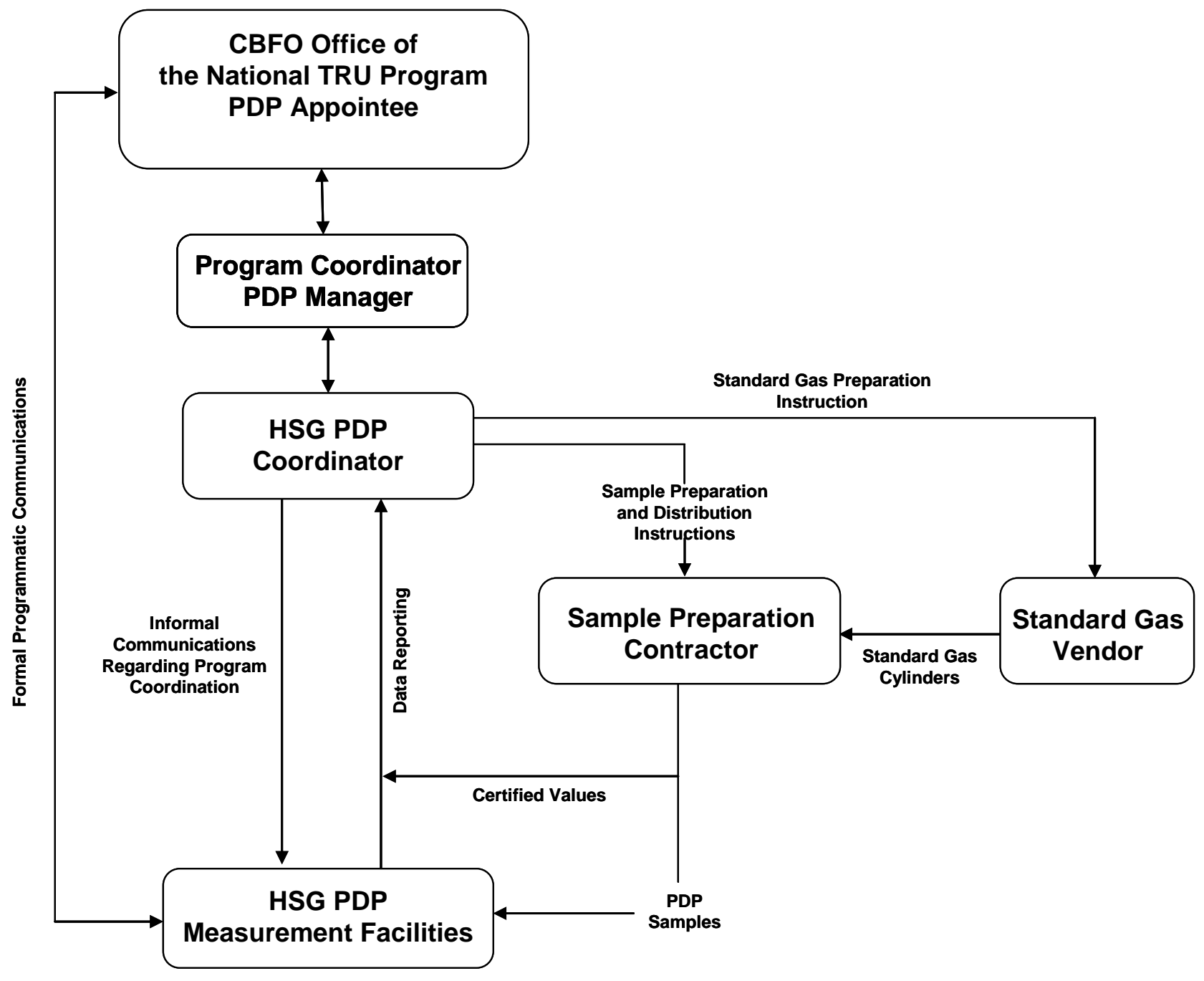

Figure 1. Organization and Information Flow for the HSG PDP 
A CBFO-designated organization functions as the program coordinator and technical advisor to CBFO. The program coordinator shall meet all of the responsibilities assigned by this plan in accordance with the requirements of the CBFO Performance Demonstration Program Management Plan (DOE/CBFO-01-3107). For the HSG PDP, the HSG PDP coordinator is responsible for the following:

- Maintains a listing of participants and their needs (such as number of canister sets required, number of systems to be approved)

- Procures standard gases from the SGV and sample preparation contractor services from the SPC ensuring all applicable procurement requirements of the QAPD are met

- Ensures preparation, control and verification of the standard gases to be used in PDP samples

- Ensures preparation, control, confirmation and distribution of PDP samples by the SPC

- Reviews procedures for PDP sample preparation

- Distributes PDP cycle schedules to measurement facility participants

- Confirms that a PDP cycle will begin at least 2 weeks prior to the planned start date

- Receives requests for extensions to the data deliverable schedule and forwards these requests to $\mathrm{CBFO}$, along with a recommendation for approval or denial for each request

- Receives, reviews, and scores the analytical data

- When applicable, receives and incorporates revisions to a participant's data submittal

- Reports performance data as specified within this document

- Reviews and provides recommendations to CBFO concerning any corrective actions required as a result of participant performance issues identified as a result of participating in the HSG PDP

- Ensures that the records of participation and results of all PDP cycles are maintained in a retrievable condition

- Provides reports and/or observations concerning the HSG PDP to CBFO for consideration

- Responds to any corrective actions identified during independent assessments of the HSG PDP

- Reviews any changes in the QAPD or WAP that affect the PDP or this plan; revises the plan when necessary

The HSG PDP coordinator provides independent technical oversight and coordination of the demonstration program to qualify participating measurement facilities and also maintains a list of the facilities currently participating in the HSG PDP. The CBFO must grant approval for each measurement facility to be a participant in this PDP. Measurement facilities that are not current participants petition the CBFO to be permitted to participate in the PDP. Each participating facility is required to provide the HSG PDP coordinator with the name, telephone number, fax 
number, and address of the contact person(s) responsible for administrative communications for the HSG PDP. Each participating facility also is required to provide an address suitable for delivery by freight and express package service of the PDP samples.

Prior to being approved for participation in the PDP, participants must submit their HSG sampling, analysis and data processing procedures to CBFO for review. Also, any time a HSG sampling and or analysis procedure is revised, it must be submitted to CBFO for review. One of the reviews conducted by $\mathrm{CBFO}$ is to determine whether the revision to the procedure may have an impact on the PDP approval status for the participant. When a procedure revision is determined to have had a possible impact on the PDP approval, CBFO may require the participant to analyze additional PDP samples to demonstrate continued acceptable performance under the revised procedure.

\section{$2.2 \quad$ Program Assessment}

The PDP is routinely assessed for efficacy and appropriateness through several interrelated activities. These activities include review and acceptance of the final testing results for each PDP cycle by the CBFO, as well as the review and approval of this plan by the CBFO. In order to assess the ongoing effectiveness of the PDP, the CBFO also considers reports and observations of the program coordinator, PDP manager, and HSG PDP coordinator; feedback from program participants; and comments from other parties such as independent QA assessors and the Corporate Board. Such communications may take any documented form, including, but not limited to, routine program correspondence, meeting minutes, action items, formal review of program documents, assessment reports, and corrective actions requests.

\subsection{Procurement}

Procurement activities necessary for conducting the PDP must comply with the QAPD. In accordance with the QAPD, the responsible purchasing organization maintains all procurement documents and performs all procurement activities.

\subsection{Training}

At a minimum, the HSG PDP Coordinator shall have at least a bachelor's degree in science or engineering and at least five years of professional experience related to volatile organic hazardous constituent analysis. Qualification and contractor training documentation shall be entered into the CBFO records system. The PDP Manager is responsible for selecting qualified personnel and ensuring that they complete the appropriate training.

Training requirements for the HSG PDP Coordinator include reading the current revision of the following documents. Completion of the reading requirement shall be documented on the form provided in attachment 1 or on an equivalent form.

- Quality Assurance Program Document (DOE/CBFO-94-1012)

- WAP

- Performance Demonstration Plan for the Analysis of Headspace Gases (DOE/CBFO-95-1076)

- $\quad$ CBFO MP 1.2, Selection of Quality Levels

- CBFO MP 3.1, Corrective Action Reports 
- CBFO MP 4.5, Generating, Receiving, Storing, and Controlling Active CBFO Project Records

- CTAC MP 2.5, Conduct of the Headspace Gas Performance Demonstration Program

- Performance Demonstration Program Management Plan (DOE/CBFO-01-3107)

- Other documents as identified by the PDP Manager

The discipline-specific training required for the HSG PDP Coordinator shall be identified in the applicable management procedure(s). Documentation of completed training is maintained in QA records in accordance with CBFO MP 4.5, Generating, Receiving, Storing, and Controlling Active CBFO Project Records. 


\subsection{PREPARATION AND DISTRIBUTION OF PDP SAMPLES}

The PDP samples, contained in SUMMA ${ }^{\circledR}$ canisters, are prepared and distributed by the SPC. The PDP samples are prepared according to directions provided by the HSG PDP coordinator. A blank for each component is also prepared. Table 2 lists suggested concentration limits for various classes for VOCs in PDP samples. The listed concentration maximums are for guidance purposes only. Final VOC concentrations in the PDP samples are left to the discretion of the HSG PDP coordinator. Any given distribution may contain canisters from all classes or any subset of classes for each program component.

Table 2. Blind Audit Sample Concentration Ranges by Class

\begin{tabular}{|l|c|c|}
\hline \multicolumn{1}{|c|}{ Canister Class } & $\begin{array}{c}\text { Concentrations } \\
\text { of Target Analytes }\end{array}$ & Notes \\
\hline Low Concentration VOC & $<150$ ppmv & 1,2 \\
High Concentration VOC & $<1000$ ppmv & 1,2 \\
Special VOC & $<1000$ ppmv & 1,2 \\
Blanks & $<50 \%$ PRQLs & 3 \\
\hline
\end{tabular}

1. May contain VOCs not on target list.

2. May contain interferents or targets with known analytical problems.

3. Pure dilution gas or zero air.

Six-liter canisters are used for all PDP samples. Canisters are cleaned, verified, and filled according to a standard operating procedure developed and approved by the SPC. PDP sample SUMMA $^{\circledR}$ canisters are filled by the SPC by means of transferring gases from cylinders containing certified standard gas mixtures. Subsequently, the SPC conducts confirmatory analyses on each standard gas mixture. Standard gas mixtures must be certified by the SGV by means of a combination of weight and analysis (depending upon component) using scales certified against weights traceable to the National Institute of Standards and Technology (NIST) or calibration standards prepared in that manner. All such certified standard gas mixtures shall have accuracy within \pm 5 percent. At the completion of standard gas preparation, the SGV provides certificates for each of the standard gases to the HSG PDP coordinator.

After all sample canisters have been shipped and the confirmatory analysis completed, the SPC shall prepare a letter report to be submitted to the HSG PDP coordinator. This report shall include the following:

- A description of all activities performed

- Identification of any problems encountered and their resolution

- A record of the distribution of canisters

- Results of all confirmatory analyses

- Any other documentation associated with the preparation and distribution of the canisters

The HSG PDP coordinator shall ensure that the SPC delivers the PDP samples to each of the measurement facilities participating in the PDP. Generally, the HSG PDP coordinator gives two weeks advance notification of the PDP sample shipping date to all participating measurement 
facilities. The PDP canisters are sent under chain-of-custody to the attention of those individuals who have been identified by the participating site (as discussed in Section 2.0). Each PDP canister is clearly labeled to allow reported results to be associated with each canister. Changes may be made to the addressee information by notifying the HSG PDP coordinator at least 48 hours before the scheduled shipping date.

Canisters used for sample distribution shall be uniquely identified and controlled by the SPC. The HSG PDP coordinator shall maintain as nonpermanent QA records the documentation associated with the acquisition of the PDP standard gases. The SPC shall maintain as nonpermanent QA records the documentation associated with sample canister cleaning, cleaning verification, sample preparation, sample concentration verification analysis and sample distribution. 


\subsection{ANALYTICAL AND DATA REPORTING REQUIREMENTS}

This section describes activities required of the participating measurement facility with respect to the PDP sample receipt, analysis, and reporting.

\subsection{Sample Receipt and Chain of Custody}

The following section describes procedures for sample receipt by participating measurement facilities (participants).

1. Immediately upon receipt of the canisters, the participant shall locate the delivery/chainof-custody (COC) record (hereafter called the COC form). Appendix A contains a sample of the COC form.

2. The participant verifies that the canisters actually received match those listed on the COC form both by serial number and physical description. The participant also verifies that the canisters have not leaked during shipping by comparing the pressure on receipt to the recorded shipping pressure.

a) If a discrepancy is noted, the participant shall notify the HSG PDP coordinator immediately. The participant shall accept delivery by noting the discrepancies on the COC form and signing it, and shall await further instructions from the HSG PDP coordinator.

b) If no discrepancies are noted, the participant shall indicate receipt by signing the $\mathrm{COC}$ form. Completion of the COC form establishes the validated time of sample receipt (VTSR).

3. Within 24 hours of sample receipt, return copies of the COC form to both the SPC and HSG PDP coordinator (one copy each). Retain the original as the COC QA record for the canisters.

\subsection{Analysis}

The participating measurement facility analyzes the contents of each canister in quadruplicate using the method(s) and procedure(s) that have been internally demonstrated and approved and that are planned for use in the WIPP waste characterization program. All analytical records and documentation generated during the performance of PDP analyses are QA records and must meet the relevant requirements in the WAP and QAPD.

Analyses should be completed and reported as soon as possible, but in any case reports must be forwarded to the HSG PDP coordinator within 28 days after the VTSR, except as noted below.

If a participant's analyses will not be reported by the due date and they desire an extension, they must notify the HSG PDP coordinator in writing (e.g., e-mail, fax) as soon as possible and request an extension. The HSG PDP coordinator will forward the request with a recommendation to the $\mathrm{CBFO}$; the request will be either granted or rejected in writing by the CBFO. All extensions must be requested and granted before the due date. If an extension has not been granted prior to the due date, the HSG PDP coordinator may make the actual identity and concentrations of the analytes in the PDP samples known at any time thereafter. Any 
participant that had not yet reported may then not be able to use these data to qualify for analysis of WIPP samples.

\subsection{Reporting}

Each PDP sample shall be analyzed in quadruplicate to help determine precision. A summary of all analytes listed in Table 1 and any tentatively identified compounds (TICs) detected for all replicate analyses, will be sent by the participating measurement facilities to the HSG PDP coordinator. The concentrations of detected analytes are to be reported irrespective of the relationships of those concentrations to detection limits quoted or demonstrated for the program. The results for analytes listed in Table 1 that are undetected in the PDP samples shall be reported as they would be for WIPP sample analyses according to the measurement facility procedures used (i.e., the MDL and a "U" flag as required by the WAP Table B3-14). The following specifications apply to the summary report:

- Reports shall be forwarded directly to the HSG PDP coordinator. Express mail or overnight delivery service is preferred; in any case, all analytical reports to the HSG PDP coordinator shall be postmarked or shipped no later than 28 calendar days after the VTSR (except as noted in Section 4.2).

- Analytical reports shall be submitted for each canister received and may be submitted for laboratory blanks analyzed in association with the PDP samples.

\subsubsection{Report Contents}

An electronic data reporting format (spreadsheet template), illustrated in Appendix B, should be used to report the data to the HSG PDP coordinator. Blank copies of these spreadsheet files are distributed with the PDP samples or may be obtained from the coordinator. The following information shall be included in the spreadsheet and hard copy report (Appendix B) for each determination:

- Identification of the reporting measurement facility and the system (equipment) on which the samples were analyzed. NOTE: The system shall be identified by a number that is permanently fixed to the system (e.g., a serial number or U.S. Government property identification number) so that movement of a system from one site to another can be tracked by the documentation of the system number used here.

- Identification of the PDP distribution cycle for which the data are being reported

- Identity of the canister by the serial number from the COC form

- Any additional identification assigned to the canister by the measurement facility

- Identification of the procedure (including revision number) used for the analysis of each analyte (the procedure number is entered in the "Method ID" column on the form provided in Appendix B)

- Identification of the replicate number corresponding to the analytical data

- Identity and concentration for each target compound or analyte identified

- Identity and estimated concentration for any TICs found 
- Date and time of analysis

- Identity of the analyst performing the PDP analysis

After this information has been entered into the electronic spreadsheet template, the spreadsheet file should be write-protected with a password known only to the participant. The results of the individual analyses must be reported, not the average of the four determinations. Data shall be reported to the HSG PDP coordinator both in electronic format and using the form in Appendix $\mathrm{B}$ or a reasonable facsimile. Regardless of whether the exact form shown in Appendix B or a facsimile is used, the number of analytes reported and the order of the analytes in the hard copy and electronic reporting shall not deviate from the order specified in Appendix B and the electronic spreadsheet template provided to the participants. The total number of pages in the report shall be indicated. The report shall include a copy of the COC form(s) for the canisters as they existed at the time of reporting. If the reports submitted are incomplete or not in compliance with instructions or these requirements, a participant might not pass a PDP cycle.

Corrections to data will be accepted if received in writing before the scoring report is completed. Corrections may be submitted by fax, if followed by mail or other transmission of the original hard copy. Verbal corrections to data will not be accepted. All corrections submitted shall include a clear explanation of the cause of the original error.

The reports shall be signed by a measurement facility staff member assigned this responsibility. Reports should contain any other information that the measurement facility feels is relevant to the data evaluation. The concentrations of all analytes that exceed the PRQLs must be quantified even if multiple dilutions of the gas sample must be analyzed (see Table 1 for PRQLs). All analytes detected at concentrations less than the PRQLs must also be quantified and reported. There is no requirement that concentrations of gases in the PDP samples be limited to any specific ratio range. (The HSG PDP coordinator ensures to the extent possible that the ratios of analytes are not so large as to be likely to cause instrument contamination.) Concentrations must be reported in parts per million by volume (ppmv) for each VOC using sample reporting criteria specified in the WAP. Data qualifying flags shall be used as follows:

B - Analyte detected in blank above the acceptable criteria

$\mathrm{E}$ - Analyte exceeds the calibration curve

$\mathrm{J}$ - Analyte less than PRQL, but greater than or equal to method detection limit (MDL)

$\mathrm{U}$ - Analyte was not detected and value is reported as the MDL

D - Analyte was quantitated from a secondary dilution or reduced sample aliquot

In addition to the analysis results, the data report shall include documentation to support identical system(s) claims as described in Appendix C.

\subsubsection{Canister Management}

In each PDP cycle all canisters should be returned to the SPC for cleaning, certification, and inventory within 2 weeks of notification of measurement facility performance. Measurement facilities that are unable to return the canisters or that wish to retain the canisters for an additional period for experimental purposes must make alternate arrangements with the HSG 
PDP coordinator. These arrangements could include replacement of canisters at the measurement facility's expense to ensure an adequate inventory of canisters in the system.

\subsection{Analytical Records}

The requirement to submit only summary data for scoring does not relieve the measurement facility from the requirement to maintain appropriate analytical records and documentation. The records generated during the analysis of the PDP samples are QA records. They must be maintained in a traceable and auditable condition. Storage conditions and duration must meet the requirements of the QAPD and other implementing QA documents and procedures. 


\subsection{EVALUATION OF PERFORMANCE DATA}

When each participant's analysis report is received, the HSG PDP coordinator evaluates the data as described in this section. The HSG PDP coordinator ensures the scored results are independently reviewed by a qualified reviewer prior to reporting the results to CBFO. The qualification requirements for the personnel assigned to review the scored results include readand-sign training on the QAPD, the HSG PDP Plan, and the program coordinator Management Procedures used to administer the HSG PDP.

Measurement facility performance is evaluated using a point score system. VOC analysis performance is evaluated in the areas of performance on blanks, accuracy, precision, and (if applicable) correct detection and identification of any TICs.

\subsection{Performance on Blanks}

Purpose: Analytical results for blanks are used to determine the presence of contamination problems and to quantify those problems if any exist.

Criterion: The criterion for blank performance is that none of the target compounds should be present in the blank analyses at levels exceeding the PRQL.

Evaluation Method: Acceptable blank performance is based on the data for all compounds and their detected concentrations relative to the PRQL, as follows:

$$
\mathrm{CB}_{\mathrm{A}}<\mathrm{PRQL}_{\mathrm{A}}
$$

where

$\mathrm{CB}_{\mathrm{A}}=$ concentration of compound $\mathrm{A}$ in blank (ppmv)

$\mathrm{PRQL}_{\mathrm{A}}=$ required quantitation limit for compound $\mathrm{A}(\mathrm{ppmv})$

Actions: If a preponderance of evidence from the participating measurement facilities indicates that a specific analyte is present in the blank at levels exceeding the PRQL, the blank is considered contaminated. The analyte data are judged unusable and deleted from consideration in the performance criteria for that particular performance demonstration.

For any compound for which the reported $\mathrm{CB}_{\mathrm{A}}$ is equal to or exceeds the $\mathrm{PRQL}_{\mathrm{A}}$ (including results reported with a "U" or "J" qualifier flag), the coordinator will note such failures in the final report, as well as any relevant observations. The impact of such failures on the measurement facility in meeting the criteria on overall scoring and performance for the cycle is described in Section 5.5. The site project manager shall be responsible for ensuring that appropriate corrective actions are taken when necessary.

\subsection{Accuracy of Quantitation}

Purpose: Analytical results for blind spikes of known concentration are used to determine the accuracy with which a measurement facility can quantitate the target compounds. 
Criterion: The results reported for the target compounds should not deviate from the reference values by more than 30 percent.

Evaluation Method: The reported analytical data are used to calculate the relative percent accuracy (RPA) for each of the target compounds as follows:

$$
\mathrm{RPA}_{\mathrm{A}}=\frac{\mathrm{ACS}_{\mathrm{A}}}{\mathrm{TC}_{\mathrm{A}}} \times 100
$$

where

$$
\begin{aligned}
& \mathrm{RPA}_{\mathrm{A}}=\begin{array}{l}
\text { relative percent accuracy expressed as percent recovery of compound } \mathrm{A} \text { in } \\
\text { the PDP sample }
\end{array} \\
& \mathrm{ACS}_{\mathrm{A}}=\begin{array}{l}
\text { average concentration of compound A from quadruplicate determinations } \\
\text { of the PDP sample (ppmv) }
\end{array} \\
& \mathrm{TC}_{\mathrm{A}}=\quad \text { reference value of compound A in the PDP sample (ppmv) }
\end{aligned}
$$

Actions: If a preponderance of evidence from the reporting measurement facilities indicates that a specific analyte falls outside the criterion of this section in the same direction, then those data may be judged inappropriate for use in determining performance for that round of performance demonstration.

For any compound for which the $\mathrm{RPA}_{\mathrm{A}}$ is outside the range of 70 to 130 percent recovery (i.e., the measured value differs from the reference value by more than \pm 30 percent) in any of the blind spikes, the coordinator will note such failures in the final report, as well as any relevant observations. The impact of such failures on the measurement facility in meeting the criteria on overall scoring and performance for the cycle is described in Section 5.5. The site project manager shall be responsible for ensuring that appropriate corrective actions are taken when necessary.

\subsection{Precision of Replicate Determinations}

Purpose: Analytical results for quadruplicate analyses of blind spikes of known concentrations are used to estimate the precision with which a measurement facility can quantitate the target compounds.

Criterion: The results reported for the target compounds of quadruplicate determinations from the same canister should not exhibit a relative standard deviation greater than 25 percent.

Evaluation Method: The analytical results for the quadruplicate determinations from each canister are used to calculate the percent relative standard deviation for each of the target compounds as follows:

$$
\% \mathrm{RSD}_{\mathrm{A}}=\frac{\mathrm{s}}{\mathrm{ACS}_{\mathrm{A}}} \times 100
$$

where 


$$
\begin{array}{lll}
\mathrm{RSD}_{\mathrm{A}}= & \begin{array}{l}
\text { relative standard deviation of the quadruplicate determinations from } \\
\text { a single canister (percent) }
\end{array} \\
\mathrm{S} & \begin{array}{l}
\text { standard deviation of the quadruplicate determinations from a single } \\
\text { canister }
\end{array} \\
\mathrm{ACS}_{\mathrm{A}}= & \begin{array}{l}
\text { average concentration of compound A in quadruplicate } \\
\text { determinations from a single canister (ppmv) }
\end{array}
\end{array}
$$

Actions: Actions are taken depending on the performance results for the precision of replicate determinations. For any compound for which the $\% \mathrm{RSD}_{\mathrm{A}}$ exceeds 25 percent, the coordinator will note such failures in the final report, as well as any relevant observations. The impact of such failures on the measurement facility in meeting the criteria on overall scoring and performance for the cycle is described in Section 5.5. The site project manager shall be responsible for ensuring that appropriate corrective actions are taken when necessary.

\subsection{Precision of Quantitation of Duplicates}

Purpose: Analytical results for duplicate blind spikes of known concentration are used to determine the precision with which a measurement facility can quantitate the target compounds.

Criterion: The difference between the results reported for the target compounds for duplicate determinations from different canisters should not exceed 25 percent of the average of the duplicate results.

Evaluation Method: The analytical results for all reported data are used to calculate the relative percent difference (RPD) for each of the target compounds as follows:

$$
\mathrm{RPD}_{\mathrm{A}}=\frac{\left|\mathrm{ACS}_{\mathrm{A}}-\mathrm{ACD}_{\mathrm{A}}\right|}{\frac{\left(\mathrm{ACS} \mathrm{A}_{\mathrm{A}}+\mathrm{ACD} \mathrm{A}_{\mathrm{A}}\right)}{2}} \times 100
$$

where

$$
\begin{aligned}
& \mathrm{RPD}_{\mathrm{A}}=\quad \begin{array}{l}
\text { relative percent difference between the averages of quadruplicate } \\
\text { determinations of two duplicate canisters }
\end{array} \\
& \mathrm{ACS}_{\mathrm{A}}=\quad \begin{array}{l}
\text { average concentration of compound A in quadruplicate } \\
\text { determinations from duplicate canister } 1(\mathrm{ppmv})
\end{array} \\
& \mathrm{ACD}_{\mathrm{A}}=\quad \begin{array}{l}
\text { average concentration of compound A in quadruplicate determinations } \\
\text { from duplicate canister } 2(\mathrm{ppmv})
\end{array}
\end{aligned}
$$

Actions: Actions are taken depending on the magnitude of the RPD between duplicate samples. For any compound for which the $\mathrm{RPD}_{\mathrm{A}}$ exceeds 25 percent, the coordinator will note such failures in the final report, as well as any relevant observations. The impact of such failures on the measurement facility in meeting the criteria on overall scoring and performance for the cycle is described in Section 5.5. The site project manager shall be responsible for ensuring that appropriate corrective actions are taken when necessary. 


\subsection{Overall Performance}

Purpose: Individual measurement facility performance on the set of PDP samples is used to assess general problems that may affect the measurement facility's ability to analyze for the compounds of interest. This conclusion could result in a holding period during which the measurement facility would not analyze WIPP samples until the causes of the problems are identified, corrective actions taken, and the efficacy of the corrective actions demonstrated.

Criteria: The criteria used to evaluate measurement facility overall performance are specified below. Criteria are applied to the data from a single PDP distribution cycle. Performance is demonstrated by achieving these criteria:

a) Measurement facilities must pass 90 percent of the accumulated performance criteria for CTCs to be considered qualified to perform VOC analysis on WIPP samples.

b) Any CTCs for which one or more of the performance criteria are failed (as defined in Sections 5.2, 5.3, or 5.4) must have been correctly identified and quantitated with an RPA between 50 and 150 percent and with a relative standard deviation (RSD) and RPD (if applicable) of $\leq 50$ percent.

c) Measurement facilities must also pass 75 percent of the accumulated performance criteria for those TCs not identified as critical to be considered qualified to perform VOC analysis on WIPP samples.

Evaluation Methods: The reported analyses are evaluated on a point scoring system, as discussed below. The reported analyses of CTCs in the PDP samples are scored as follows:

a) For CTCs present in the duplicate canisters, the measurement facility receives five points for each evaluated RPA, RSD, and RPD that meets the criteria of Sections 5.2, 5.3 , and 5.4, respectively (possible 25 points per compound).

b) For CTCs present in a single canister, the measurement facility receives five points for each evaluated RPA and RSD that meets the criteria of Sections 5.2 and 5.3, respectively (possible 10 points per compound).

The reported analyses of TCs in the PDP samples are scored as follows:

a) For TCs present in the duplicate canisters, the measurement facility receives five points for each evaluated RPA, RSD, and RPD that meets the criteria of Sections 5.2, 5.3 , and 5.4, respectively (possible 25 points per compound).

b) For TCs present in a single canister, the measurement facility receives five points for each evaluated RPA and RSD that meets the criteria of Sections 5.2 and 5.3, respectively (possible 10 points per compound).

For each compound that is known to be present in any canister but that is neither a CTC nor a $\mathrm{TC}$, the measurement facility receives five points for correctly identifying the compound as a TIC (possible five points per compound). 
Each measurement facility starts with 63 points for each blank canister (five points for each CTC and one point for each TC). From this total the measurement facility loses five points for each CTC and one point for each TC for which the measurement facility fails to meet the blank criteria of Section 5.1 .

Each measurement facility loses one point for each false positive (i.e., identification of a CTC or TC with a mean concentration at or greater than the PRQL) in a canister in which the compound is known to be absent. This criterion does not apply to the blank canister, which is evaluated as above, or to false positive identification of TICs for which no points are deducted.

Example Calculation: Measurement facility A receives five canisters grouped as follows:

C Canister 1 is a blank

C Canisters 2 and 3 are duplicates, each containing six CTCs and five TCs

C Canister 4 contains five CTCs, seven TCs, and one TIC

C Canister 5 contains one CTC and three TCs

The measurement facility can score a maximum of 255 CTC points and 247 TC points, broken down as follows:

C Canister $1=45$ CTC points $(9 \times 5)$ and 18 TC points $(18 \times 1)$

C Canisters 2 and $3=150$ CTC points $(6 \times 25)$ and 125 TC points $(5 \times 25)$

C Canister $4=50$ CTC points $(5 \times 10), 70$ TC points $(7 \times 10)$, and five TIC points

C Canister $5=10$ CTC points $(1 \times 10)$ and 30 TC points $(3 \times 10)$

Measurement facility CTC score $(\%)=100 \times\left(\mathrm{P}_{\mathrm{CTC}} / 255\right)$

Measurement facility TC score $(\%)=100 \times\left(\mathrm{P}_{\mathrm{TC}} / 248\right)$

where

$$
\begin{aligned}
& \mathrm{P}_{\mathrm{CTC}}=\text { the total number of CTC points scored by the measurement facility } \\
& \mathrm{P}_{\mathrm{TC}}=\text { the total number of TC points scored by the measurement facility }
\end{aligned}
$$

Canister or Analyte Disqualification: If the preponderance of evidence from the participating measurement facilities supports a conclusion that the concentration of a specific analyte in a canister has not been certified accurately enough to demonstrate compliance with the criteria of the PDP, the HSG PDP coordinator may judge the data for that analyte to be inappropriate for use in evaluating performance for that particular performance demonstration.

Actions: The site project manager shall be responsible for ensuring that appropriate corrective actions are implemented when a measurement facility exceeds an action level. The following criteria are used to determine when an action level is exceeded:

a) If a measurement facility obtains a score of less than 90 percent of the total possible CTC points, the measurement facility is judged to have exceeded an action level. 
b) If a measurement facility obtains a score of equal to or greater than 90 percent but less than 100 percent of the total possible CTC points, the measurement facility is judged to have exceeded an action level, unless those analytical results that failed the criteria of Sections 5.2, 5.3, or 5.4 were able to meet criteria of $\geq 50$ percent and $\leq 150$ percent for the RPA and $\leq 50$ percent for the RSD and RPD (as applicable).

c) If a measurement facility obtains a score of less than 75 percent of the total possible TC points, the measurement facility is judged to have exceeded a control level. Measurement facilities that are presently qualified from a previous WIPP performance demonstration are placed on probation. Probationary status will be removed if the measurement facility scores greater than 75 percent of the TC points on the next PDP sample set. Measurement facilities that score less than 75 percent of the TC points on the initial PDP sample set or score less than 75 percent of the TC points on two consecutive sample sets (after initially qualifying) are judged to have exceeded an action level.

d) Action or control levels are not defined for identification of TICs and the points received for TIC identification. When TICs are included in the PDP samples, they provide an indicator of the measurement facility's ability to identify these analytes. The use of TICs in PDP samples only provides the measurement facility information regarding the effectiveness of the TIC identification procedures and as a method to ensure that the procedures used to analyze WIPP samples are also being fully implemented to analyze PDP samples. TICs are not analytes required by the WIPP permit unless a specific TIC appears in the 20.4.1.200 NMAC (incorporating 40 CFR §261) Appendix VIII and it is reported in $>25 \%$ of the waste containers sampled from a given waste stream, at which point that compound is added to the target analyte list for the applicable waste stream. It is not appropriate to require a measurement facility to take an action or to require a probationary status as a result of poor performance on these analytes in PDP samples.

Any measurement facility that has exceeded an action level shall:

a) Investigate the cause(s) of the failure(s) and take corrective action.

b) Generate sufficient data to demonstrate that the same problems will not recur.

c) Within 30 days of receipt of the scoring report, submit a report of corrective actions to the CBFO addressing (a) and (b) above. This report also shall include an assessment of the impact of the facility's approval status for headspace gas analysis on waste characterization activities.

CBFO may elect to grant "conditional approval" status for a measurement facility to perform waste characterization analyses for this program if such conditional approval will not compromise the overall quality of the data being generated for the program. Such a conditional approval may be granted if:

a) The report of corrective actions demonstrates that the problems or deficiencies that resulted in the measurement facility exceeding an action level have been corrected, and/or 
b) Limitations and conditions can be placed on the approval to guarantee that suspect data will not be used in the program.

The potential causes for exceeding an action level are so many and varied that the measurement facility may choose to proceed at risk or cease operations until corrective actions have been completed. The measurement facility should recognize that data obtained before the action level was exceeded and any data obtained at risk may be found to be unacceptable to WIPP. 


\subsection{REPORTING OF PERFORMANCE DATA}

\subsection{Summary of Data}

The HSG PDP coordinator shall review and evaluate the results, compile them into a master summary scoring report, and deliver this report to the $\mathrm{CBFO}$ within approximately five weeks after receipt of the last measurement facility data set. The scoring report shall include the values reported by the measurement facilities, the reference concentration values, the acceptance ranges, and the pass/fail status of each individual measurement facility.

The CBFO, in conjunction with the HSG PDP coordinator and PDP manager, evaluates individual measurement facility performance and approves individual measurement facilities for participation in the WIPP waste characterization program. Depending on the results of the PDP, the TRU waste site project manager(s) shall be responsible for ensuring that appropriate corrective actions are taken.

\subsection{Distribution of Data}

Copies of the scoring report shall be distributed to each of the DOE Operations Offices involved, to each of the participating measurement facilities, and to such other individuals and organizations as deemed appropriate by the CBFO. The CBFO shall also provide written notification to the DOE Operations Offices regarding the adequacy and approval status of their participating measurement facilities.

\subsection{Measurement Facility Status}

In accordance with the WAP, once the CBFO has determined measurement facility status as "approved" with respect to analyses that are required by the WIPP to demonstrate compliance with regulatory requirements, that status shall remain in effect for a maximum of 13 months (i.e., 12 months plus a one-month "grace" period). All measurement facilities must participate in the annual primary cycle in order to remain qualified to perform WIPP analyses. A timely response in the annual primary cycle will ensure that a measurement facility will not exceed their qualification time limit. If a measurement facility revises an analytical method or adds new instrumentation, CBFO must approve the changes/addition. If no CBFO approval is received for these changes/addition, all data generated between the time of change/addition and either approval by CBFO or successful participation in an annual primary cycle will be considered to be "at risk." The CBFO approval of the change/addition may (or may not) require analysis of PDP samples.

The qualification period for a measurement facility begins with the date that analyses in a PDP cycle are completed. After the end of the 13th month, a measurement facility that has not yet successfully completed their analyses of PDP samples to requalify their method may choose to proceed at risk with WIPP analyses or cease operations. The measurement facility should recognize that data obtained at risk may be found to be unacceptable to WIPP. Data generated at risk cannot be used for certifying waste for shipment to WIPP until: 
- $\quad$ The system used to collect the data passes the PDP, and

- The data have been reconciled through the dispositioning of a nonconformance report. 


\subsection{RECORDS}

The records for the HSG PDP are identified and listed in Table 3. In accordance with the CBFO QAPD, QA records are identified. Also specified is the organization responsible for maintaining each record in accordance with CBFO QAPD requirements. Non-QA records are maintained in accordance with standard practice for working or project files as used by the organization maintaining the records. In addition, the HSG PDP coordinator may determine that records of other program activities are QA records and enter them into the QA records system with the same level of control and maintenance.

These QA records may be organized by HSG PDP Plan revision, by PDP cycle, or other principle, as applicable. These records are nonpermanent records and shall be maintained in accordance with the QAPD requirements. Records disposition, when applicable, will be in accordance with CBFO requirements and approved procedures. All QA records identified in this plan shall be stored in accordance with record storage requirements in the QAPD. Access to QA records is limited to personnel involved in the program or having related QA or records custodial responsibilities.

Table 3. Headspace Gas PDP Documentation/Records List

\begin{tabular}{|c|c|c|c|}
\hline Documents(s) & $\begin{array}{c}\text { QA } \\
\text { Record }\end{array}$ & $\begin{array}{l}\text { Storage } \\
\text { Location }\end{array}$ & Comments \\
\hline $\begin{array}{l}\text { 1. Participant program } \\
\text { documentation } \\
\text { - Procedures, raw data, } \\
\text { calibration records, } \\
\text { training records }\end{array}$ & Yes & Participant & $\begin{array}{l}\text { These are the same as those used in waste } \\
\text { characterization activities. }\end{array}$ \\
\hline $\begin{array}{l}\text { 2. Participant data package, as } \\
\text { specified in the PDP Plan }\end{array}$ & Yes & $\mathrm{CBFO}$ & Transmitted to CBFO with scoring report. \\
\hline $\begin{array}{l}\text { 3. Procurement records for } \\
\text { purchase of standard gases } \\
\text { and sample preparation } \\
\text { contractor (SPC) services. }\end{array}$ & Yes & $\begin{array}{l}\text { Program } \\
\text { Coordinator }\end{array}$ & $\begin{array}{l}\text { Documentation will specify QA } \\
\text { requirements to the standard gas vendor } \\
\text { (SGV) and SPC. }\end{array}$ \\
\hline $\begin{array}{l}\text { 4. SPC sample prep report, as } \\
\text { specified in the PDP Plan, } \\
\text { including: } \\
\text { - Narrative } \\
\text { - Confirmatory analysis } \\
\text { results } \\
\text { - Listing of } \\
\text { canisters/recipients }\end{array}$ & Yes & $\mathrm{CBFO}$ & Transmitted to CBFO with scoring report. \\
\hline $\begin{array}{l}\text { 5. SP Work Plan and } \\
\text { procedure for sample } \\
\text { preparation }\end{array}$ & Yes & SPC & $\begin{array}{l}\text { Maintained according to SPC QA Plan } \\
\text { requirements; assessed for adequacy by the } \\
\text { program coordinator during initial } \\
\text { procurement of the SPC and at least every } \\
\text { three years subsequently. The SPC QA } \\
\text { requirements must include retention of these } \\
\text { records as nonpermanent QA records to } \\
\text { meet QAPD requirements. }\end{array}$ \\
\hline
\end{tabular}




\begin{tabular}{|c|c|c|c|}
\hline Documents(s) & $\begin{array}{c}\text { QA } \\
\text { Record }\end{array}$ & $\begin{array}{c}\text { Storage } \\
\text { Location }\end{array}$ & Comments \\
\hline 6. SPC supporting procedures & No & SPC & $\begin{array}{l}\text { Maintained according to SPC QA Plan } \\
\text { requirements; assessed for adequacy by the } \\
\text { program coordinator during initial } \\
\text { procurement of the SPC and at least every } \\
\text { three years subsequently. The SPC QA } \\
\text { requirements must include retention of these } \\
\text { records as nonpermanent QA records to } \\
\text { meet QAPD requirements. }\end{array}$ \\
\hline $\begin{array}{l}\text { 7. SPC personnel } \\
\text { training/qualification records }\end{array}$ & No & SPC & $\begin{array}{l}\text { Maintained according to SPC QA Plan } \\
\text { requirements; assessed for adequacy by the } \\
\text { program coordinator during initial } \\
\text { procurement of the SPC and at least every } \\
\text { three years subsequently. The SPC QA } \\
\text { requirements must include retention of these } \\
\text { records as nonpermanent QA records to } \\
\text { meet QAPD requirements. }\end{array}$ \\
\hline $\begin{array}{l}\text { 8. Standard Gas Vendor } \\
\text { contractor QA } \\
\text { program/procedures/training } \\
\text { \& qualification records, etc. }\end{array}$ & No & SGV & $\begin{array}{l}\text { Maintained according to SGV QA Plan } \\
\text { requirements for "certified" standards; } \\
\text { assessed for adequacy by the program } \\
\text { coordinator at least every three years. The } \\
\text { SGV QA requirements must include } \\
\text { retention of these records as nonpermanent } \\
\text { QA records to meet QAPD requirements. }\end{array}$ \\
\hline 9. SPC QA Program Plan & Yes & SPC & $\begin{array}{l}\text { General facility program plan; not specific to } \\
\text { PDP support activities. }\end{array}$ \\
\hline $\begin{array}{l}\text { 10. SPC-generated operational } \\
\text { records (e.g., lab notebooks, } \\
\text { etc.) including standard gas } \\
\text { certification sheets from } \\
\text { standards preparation } \\
\text { contractor }\end{array}$ & Yes & SPC & \\
\hline $\begin{array}{l}\text { 11. Schedule notification letters } \\
\text { sent to participants; includes } \\
\text { confirmation of shipping info } \\
\text { on canisters and return of all } \\
\text { canisters to SPC }\end{array}$ & Yes & $\mathrm{CBFO}$ & \\
\hline 12. Scoring report & Yes & $\mathrm{CBFO}$ & $\begin{array}{l}\text { CBFO approves issuance to DOE field } \\
\text { offices and participants, program coordinator } \\
\text { retains file copy. }\end{array}$ \\
\hline $\begin{array}{l}\text { 13. Transmittal letter to } \mathrm{CBFO} \\
\text { with scoring report }\end{array}$ & Yes & CBFO & Same as item 12 \\
\hline $\begin{array}{l}\text { 14. Letters issued by CBFO to } \\
\text { distribute scoring report } \\
\text { and/or to provide status } \\
\text { notification to participants }\end{array}$ & Yes & $\mathrm{CBFO}$ & $\begin{array}{l}\text { Program coordinator maintains a current } \\
\text { project file copy. }\end{array}$ \\
\hline $\begin{array}{l}\text { 15. SPC letters to participants } \\
\text { accompanying canisters }\end{array}$ & Yes & SPC & \\
\hline $\begin{array}{l}\text { 16. Chain-of-custody forms with } \\
\text { canisters }\end{array}$ & Yes & Participants & $\begin{array}{l}\text { Copy included as part of participant's data } \\
\text { package submittals. }\end{array}$ \\
\hline
\end{tabular}




\begin{tabular}{|c|c|c|c|}
\hline Documents(s) & $\begin{array}{c}\text { QA } \\
\text { Record }\end{array}$ & $\begin{array}{c}\text { Storage } \\
\text { Location }\end{array}$ & Comments \\
\hline $\begin{array}{l}\text { 17. Electronic reporting/scoring } \\
\text { software documentation, } \\
\text { validation, instructions }\end{array}$ & Yes & CBFO & $\begin{array}{l}\text { In compliance with CBFO QAPD. } \\
\text { Submitted to CBFO with scoring report } \\
\text { when applicable. }\end{array}$ \\
\hline $\begin{array}{l}\text { 18. Tasking documentation issued } \\
\text { to SPC by program } \\
\text { coordinator for sample } \\
\text { preparation }\end{array}$ & Yes & $\mathrm{CBFO}$ & CBFO copied on all letters/CTAC file copy. \\
\hline $\begin{array}{l}\text { 19. Letters from potential } \\
\text { participants requesting } \\
\text { participation }\end{array}$ & Yes & $\mathrm{CBFO}$ & \\
\hline $\begin{array}{l}\text { 20. Participant letters requesting } \\
\text { time extension for submitting } \\
\text { results }\end{array}$ & Yes & $\mathrm{CBFO}$ & $\begin{array}{l}\text { Letters or e-mail addressed to HSG PDP } \\
\text { coordinator. If in letter form, submitted to } \\
\text { CBFO with scoring report. If e-mail, } \\
\text { retained by HSG PDP Coordinator in } \\
\text { electronic format and forwarded to CBFO } \\
\text { with recommendation for approval. }\end{array}$ \\
\hline $\begin{array}{l}\text { 21. Responses to extension } \\
\text { requests }\end{array}$ & Yes & CBFO & Responses issued by CBFO. \\
\hline $\begin{array}{l}\text { 22. PDP Plan/revisions and } \\
\text { Management Plan/revisions }\end{array}$ & Yes & $\mathrm{CBFO}$ & \\
\hline $\begin{array}{l}\text { 23. PDP Plan and Management } \\
\text { Plan revision review } \\
\text { comments/resolutions }\end{array}$ & Yes & $\mathrm{CBFO}$ & \\
\hline 24. Electronic reporting diskettes & No & $\begin{array}{l}\text { Program } \\
\text { Coordinator }\end{array}$ & $\begin{array}{l}\text { Diskette verified against hard copy. Only } \\
\text { current cycle retained. }\end{array}$ \\
\hline 25. Traveler & Yes & $\mathrm{CBFO}$ & $\begin{array}{l}\text { One-page document generated to record } \\
\text { receipt of data package, review/acceptance } \\
\text { of data, scoring results, and completion of all } \\
\text { scoring activities for each participant. } \\
\text { Transmitted to CBFO as part of scoring } \\
\text { report packages. }\end{array}$ \\
\hline $\begin{array}{l}\text { 26. Participant transmittals to } \\
\text { correct errors in original data } \\
\text { submittal letter plus revised } \\
\text { data }\end{array}$ & Yes & $\mathrm{CBFO}$ & Transmitted to CBFO with scoring report. \\
\hline 27. CTAC PDP training records & Yes & $\mathrm{CBFO}$ & Submitted with applicable scoring report. \\
\hline $\begin{array}{l}\text { 28. Current document/software } \\
\text { revision list }\end{array}$ & Yes & $\mathrm{CBFO}$ & $\begin{array}{l}\text { Required by CBFO QAPD; submitted with } \\
\text { applicable scoring report. }\end{array}$ \\
\hline $\begin{array}{l}\text { 29. HSG PDP Management } \\
\text { Procedure }\end{array}$ & Yes & $\begin{array}{l}\text { Program } \\
\text { Coordinator }\end{array}$ & $\begin{array}{l}\text { CBFO reviews to ensure MP meets } \mathrm{CBFO} \\
\text { requirements. }\end{array}$ \\
\hline $\begin{array}{l}\text { 30. Participants' reports of } \\
\text { corrective actions }\end{array}$ & Yes & $\mathrm{CBFO}$ & Submitted to CBFO. \\
\hline
\end{tabular}




\subsection{GLOSSARY}

ACCURACY - The degree of agreement between a measured value and an accepted reference of the true value. Accuracy is determined as the percent recovery.

ACTION LEVEL - A numerical criterion that must be met for a type of analysis, e.g., a fraction of percent recoveries that must fall within the respective QAOs. Failure to meet this criterion may result in a conclusion that the measurement facility is unable to adequately perform a specific type of analysis.

ANALYSIS DATE/TIME - The date and military time (24-hour clock) of the introduction of the sample, standard, or blank into the analysis system.

ANALYTE - The element, ion, or compound an analysis seeks to determine; the element of interest.

ANALYTICAL METHOD - The sample preparation and instrumentation procedures or steps that must be performed to estimate the quantity of analyte in a sample.

AUDIT - A planned and documented independent assessment to determine by investigation, examination, or evaluation of objective evidence the adequacy of and compliance with established procedures, instructions, drawings, and other applicable documents, and the effectiveness of implementation. An audit should not be confused with surveillance or inspection activities performed for the sole purpose of process control or product acceptance.

BLIND AUDIT SAMPLE - A sample of known composition, provided as a single-blind sample to the analytical measurement facility, and used by DOE to evaluate analytical measurement facility performance. Blind audit samples are distributed to participating measurement facilities as part of the PDP.

CHAIN OF CUSTODY - A set of procedures established to ensure that the integrity of the sample and that of the sample data are maintained.

CORRECTIVE ACTION - Measures taken to rectify conditions adverse to quality and, where necessary, to preclude their recurrence.

CRITICAL TARGET COMPOUNDS - VOCs that have been identified in the WAP as having special significance with respect to hazardous waste characterization. CTCs are identified in Table 1.

DUPLICATE - A second aliquot of a sample that is treated the same as the original sample to determine the precision of the method.

HSG PDP COORDINATOR - An individual responsible for coordinating the technical operations of the HSG PDP, including HSG sample component preparation, subcontractor oversight, scheduling, scoring, and report summary preparation.

INTERFERENTS - Substances that affect the analysis for the element or compound of interest. 
LABORATORY BLANK - An analyte-free matrix to which all reagents are added in the same volumes or proportions as used in sample analysis. The laboratory blank is used to document contamination resulting from the measurement facility sample preparation and analytical process.

PDP MANAGER - An individual responsible for overall performance of, and coordination among, the three elements of the PDP (HSG, RCRA, and NDA).

PDP SAMPLE - A blind audit sample prepared specifically for use in the PDP.

PERCENT RELATIVE STANDARD DEVIATION - A calculated value used to evaluate the precision of measurements made on quadruplicate analyses of a single PDP sample. The percent relative standard deviation $(\% \mathrm{RSD})$ is calculated as:

$$
\% \mathrm{RSD}_{\mathrm{A}}=\frac{\mathrm{s}}{\mathrm{ACS}_{\mathrm{A}}} \times 100
$$

where

$$
\begin{array}{ll}
\mathrm{RSD}_{\mathrm{A}}= & \begin{array}{l}
\text { relative standard deviation of the quadruplicate determinations from } \\
\text { a single canister (percent) }
\end{array} \\
\mathrm{S} & \begin{array}{l}
\text { standard deviation of the quadruplicate determinations from a single } \\
\text { canister }
\end{array} \\
\mathrm{ACS}_{\mathrm{A}}=\quad \begin{array}{l}
\text { average concentration of compound A in quadruplicate } \\
\text { determinations from a single canister }(\mathrm{ppmv})
\end{array}
\end{array}
$$

PRECISION - A measure of mutual agreement among individual measurements of the same property made under prescribed similar conditions; often expressed as a standard deviation or relative percent difference.

PROCEDURE - A detailed, step-by-step description of the sequence of actions to be followed to perform a given task or activity. A procedure also includes instructions and drawings. If followed in sequence, a procedure provides enough information that a trained person could complete the task without additional information.

PROGRAM COORDINATOR - A CBFO-designated organization that administers and coordinates PDP functions. The program coordinator will designate the PDP manager.

PROGRAM REQUIRED QUANTITATION LIMIT - Level of VOC analyte quantitation under the WAP that causes specified actions. The PRQLs establish the values on measured analyte concentrations that meet program goals or cause specific actions to be taken. For example, for each target analyte in a waste stream, the PRQL is compared with the UCL 90 . If the $\mathrm{UCL}_{90}$ for the analyte is greater than or equal to the PRQL, the EPA hazardous waste number for that analyte may be assigned to the waste stream. PRQLs are presented in Table 1. 
QUALITY ASSURANCE - All those planned and systematic actions necessary to provide adequate confidence that an item will perform satisfactorily in service.

QUALITY ASSURANCE OBJECTIVES - The characteristics of data that are associated with their ability to satisfy a given purpose or objective. The characteristics of major importance are accuracy, precision, completeness, representativeness, and comparability.

RECOVERY - The numerical ratio of the amount of analyte measured by the laboratory method divided by the known amount of analyte added to the matrix (i.e., spiked sample) to be analyzed. This ratio is usually expressed as a percentage.

RELATIVE PERCENT ACCURACY - A calculated value used to evaluate the accuracy of measurements made on quadruplicate analyses of the PDP samples. The relative percent accuracy (RPA) is calculated as:

$$
\mathrm{RPA}_{\mathrm{A}}=\frac{\mathrm{ACS}_{\mathrm{A}}}{\mathrm{TC}_{\mathrm{A}}} \times 100
$$

where

$$
\begin{aligned}
& \mathrm{RPA}_{\mathrm{A}}=\text { relative percent accuracy expressed as percent recovery of compound } \mathrm{A} \text { in } \\
& \text { the PDP sample } \\
& \mathrm{ACS}_{\mathrm{A}}=\text { average concentration of compound } \mathrm{A} \text { from quadruplicate determinations } \\
& \text { of the PDP sample (ppmv) } \\
& \mathrm{TC}_{\mathrm{A}}=\text { reference value of compound } \mathrm{A} \text { in the PDP sample (ppmv) }
\end{aligned}
$$

RELATIVE PERCENT DIFFERENCE - A calculated value use to evaluate the precision of measurements made on quadruplicate analyses of the duplicate PDP samples. The relative percent difference (RPD) is calculated as:

$$
\mathrm{RPD}_{\mathrm{A}}=\frac{\left|\mathrm{ACS}_{\mathrm{A}}-\mathrm{ACD}_{\mathrm{A}}\right|}{\frac{\left(\mathrm{ACS_{ \textrm {A } }}+\mathrm{ACD} \mathrm{A}_{\mathrm{A}}\right)}{2}} \times 100
$$

where

$$
\begin{aligned}
& \mathrm{RPD}_{\mathrm{A}}=\quad \begin{array}{l}
\text { relative percent difference between the averages of quadruplicate } \\
\text { determinations of two duplicate canisters }
\end{array} \\
& \mathrm{ACS}_{\mathrm{A}}=\quad \begin{array}{l}
\text { average concentration of compound } \mathrm{A} \text { in quadruplicate } \\
\text { determinations from duplicate canister } 1 \text { (ppmv) }
\end{array} \\
& \mathrm{ACD}_{\mathrm{A}}=\quad \begin{array}{l}
\text { average concentration of compound A in quadruplicate determinations } \\
\text { from duplicate canister } 2(\mathrm{ppmv})
\end{array}
\end{aligned}
$$

SAMPLE - A portion of material to be analyzed that is contained in single or multiple containers and identified by a unique sample number.

SAMPLE PREPARATION CONTRACTOR - An independent contractor responsible for the actual preparation and shipping of the PDP samples. The SPC is responsible for maintaining the 
canister inventory, cleaning canisters prior to use for PDP samples, and ensuring the traceability of the reference standards used to prepare the PDP samples.

STANDARD DEVIATION - The square root of the variance of a set of values.

STANDARD GAS VENDOR - An independent contractor responsible for the actual preparation and shipping of the cylinders of reference standard-grade gas mixes that are used to prepare the PDP samples.

SUMMA ${ }^{\circledR}$ CANISTER - A stainless-steel pressure vessel with SUMMA ${ }^{\circledR}$ passivated interior surfaces for the collection and storage of gas samples. The SUMMA ${ }^{\circledR}$ passivation process involves the formation of chromium-nickel oxide on the interior surface of the canister. This type of canister is used for sample storage stability of many specific organic compounds.

TARGET COMPOUNDS - Those noncritical VOCs identified by the program as analytes. Target compounds for the program are listed in Table 1.

TENTATIVELY IDENTIFIED COMPOUNDS - Nontarget compounds identified during the analysis of PDP samples. Concentrations reported for these compounds will have a higher uncertainty associated with them than the reported concentrations for target analytes.

TRANSURANIC WASTES - Laboratory and process wastes that contain alpha-emitting radionuclides of atomic number greater than 92 (e.g., the radioactive isotopes of plutonium), have half-lives longer than 20 years, and are present in concentrations greater than 100 nanocuries per gram of waste.

VALIDATED TIME OF SAMPLE RECEIPT - The documented date and time at which a sample is received at the analytical facility, as recorded on the chain-of-custody form.

VARIANCE - A measure of the dispersion of a series of results around their average. It is the sum of the squares of the individual deviations from the average of the results, divided by the number of results minus one.

VOLATILE ORGANIC COMPOUNDS - For the purposes of the program, those VOCs listed in Table 1 and any additional compounds tentatively identified by the VOC analytical procedures used to satisfy program requirements.

WORK CELL - A well-defined group of analysts that together perform the method analysis. The members of the group and their specific functions within the work cell must be fully documented (EPA 2003). 


\subsection{REFERENCES}

DOE/CBFO-94-1012, Quality Assurance Program Document, current revision, U.S. Department of Energy Carlsbad Field Office.

DOE/CBFO-01-1005, Performance Demonstration Program Plan for Nondestructive Assay of Drummed Wastes for the TRU Waste Characterization Program, current revision, U.S. Department of Energy Carlsbad Field Office.

DOE/CBFO-01-1006, Performance Demonstration Program Plan for Nondestructive Assay of Boxed Wastes for the TRU Waste Characterization Program, current revision, U.S. Department of Energy Carlsbad Field Office.

DOE/CBFO-95-1077, Performance Demonstration Program Plan for RCRA Constituent Analysis of Solidified Wastes, current revision, U.S. Department of Energy Carlsbad Field Office.

DOE/CBFO-01-3107, Performance Demonstration Program Management Plan, current revision, U.S. Department of Energy Carlsbad Field Office.

EPA 2003, EPA/600/R-04/003, National Environmental Laboratory Accreditation Conference, 2003 NELAC Standard, June 5, 2003.

NM4890139088-TSDF, as modified, Waste Isolation Pilot Plant Hazardous Waste Facility Permit, New Mexico Environment Department, Santa Fe, New Mexico. 


\section{APPENDIX A}

\section{Example Chain-of-Custody Form}


WIPP WASTE CHARACTERIZATION PROGRAM LABORATORY PERFORMANCE DEMONSTRATION

\section{Delivery/Chain-of-Custody Record}

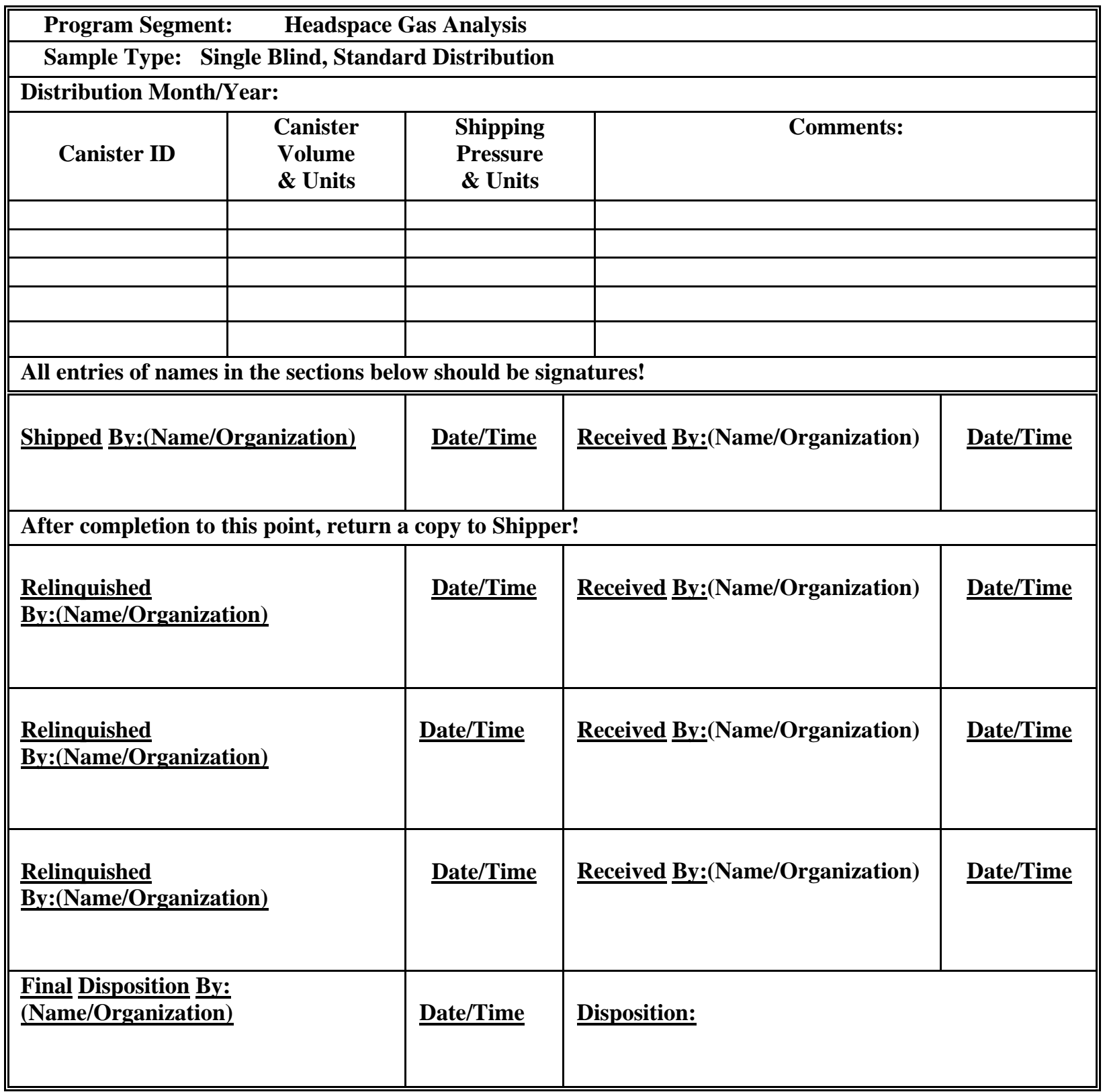




\section{APPENDIX B}

\section{Example Data Reporting Form}




\section{PERFORMANCE DEMONSTRATION PROGRAM REPORT FORM HEADSPACE GAS ANALYSIS - VOLATILES}

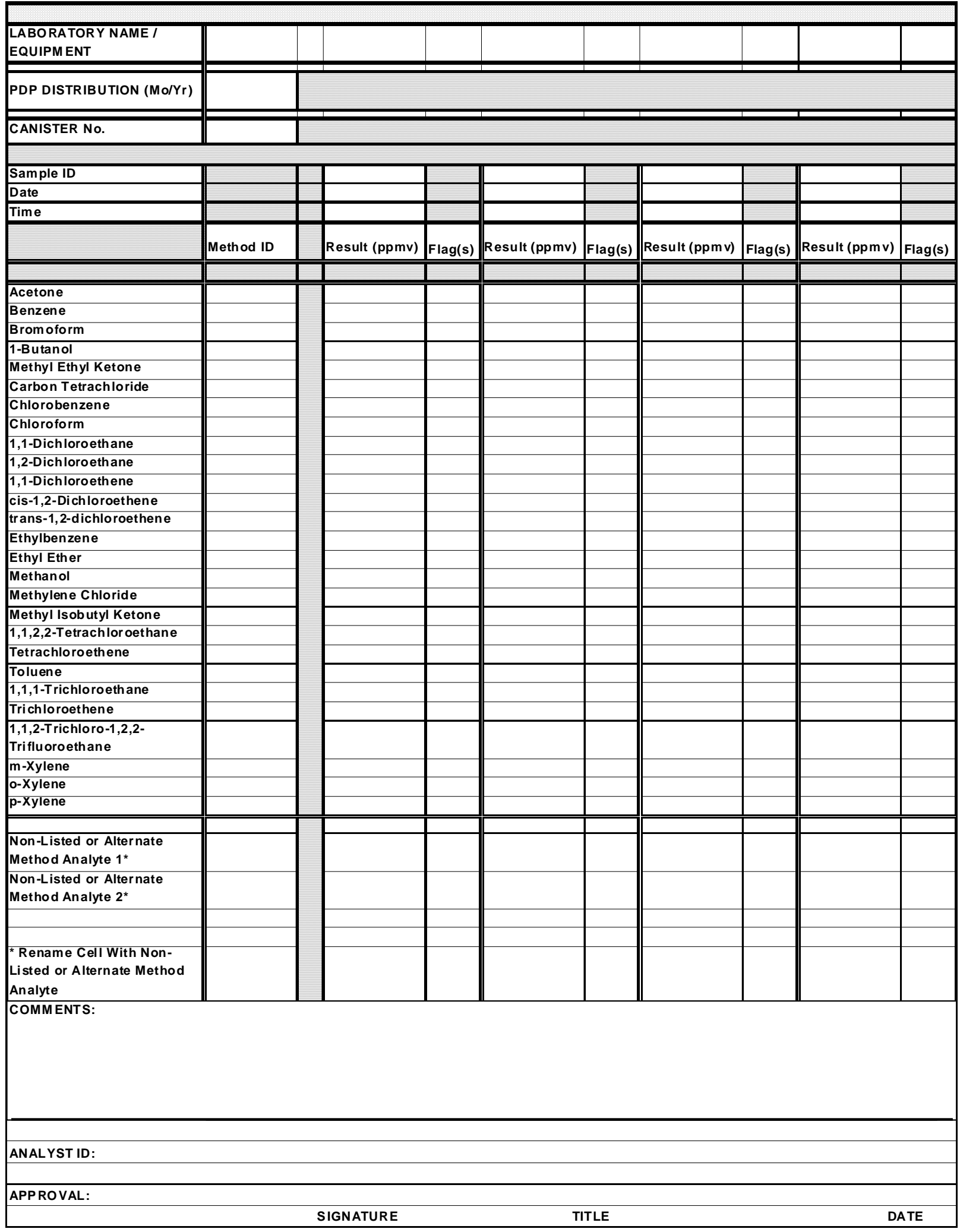




\section{APPENDIX C}

\section{Criteria for Identical Analytical Systems} for the Headspace Gas PDP 


\section{CRITERIA FOR IDENTICAL ANALYTICAL SYSTEMS FOR THE HEADSPACE GAS PDP}

Each manufacturer or owner/operator making a claim of identical analytical systems shall submit a document to the HSG PDP coordinator identifying the systems and addressing each of the criteria used to define identical systems. The method performance data maintained by the operators of identical systems must include comparisons of expected and actual performance between the systems. Procedures must be in place to ensure that the identical status of the systems is maintained and to inform $\mathrm{CBFO}$ and the affected sites immediately of any deviation from this status.*

For headspace gas analytical systems to be considered to be identical, the systems should meet all of the following criteria (NOTE: CBFO may request additional information for evaluating identical system status if the information submitted is not considered adequate):

1. Within each system, each quality-affecting component must have the same manufacturer and model number or be documented to have the same construction and/or performance specifications (i.e., same GC column used, same scan rate and mass range used for the mass spectrometer).

2. Each deployed system must have the same configuration, including all quality affecting manufacturer options.

3. Each deployed system must use the same method of sample delivery to the instrument.

4. Each deployed system must use the same procedures for calibration and operational QC checks, including a routine intercomparison, e.g., analysis of the same control samples.

5. Each deployed system must use the same procedures for operation, including record keeping.

6. Each deployed system must use the same software and procedures for data reduction, review, and reporting.

7. Each deployed system must have the same qualification, training, and performance testing for the operating personnel or personnel reporting data.

8. Each deployed system must be operated by the same work cell.

9. Each deployed system must be operated under the same management structure and Quality Assurance Plan.

10. Each deployed system must use verification and calibration standards with identical traceability.

11. Each deployed system must conduct analyses in accordance with the same written analytical procedure(s).

*Minor tuning/setting adjustment differences between otherwise identical systems does not constitute a deviation from their identical status. 


\section{ADDITIONAL CRITERIA FOR QUALIFICATION OF MOBILE ANALYTICAL SYSTEMS FOR THE HEADSPACE GAS PDP}

The use of mobile gas chromatography/mass spectrometry systems to support TRU waste characterization introduces a concern relative to the identical systems criteria stated in Appendix C. Specifically, the identical systems criteria that may change when a system is moved between HSG PDP cycles (e.g., the criteria that state that each deployed system must be operated under the same management structure and Quality Assurance Plan) become an issue. To accommodate the need to maintain system qualification, and to keep the costs of the PDP reasonable (i.e., not require supplemental PDP cycles each time mobile systems are moved), all criteria stated in Appendix C and one additional criterion must be observed by operators of mobile HSG analysis systems. This criterion applies only when the system to be moved does not meet all of the identical systems criteria with a PDP-approved system at the new location or when the moved system will become the only operational system at the new location. The additional criterion is:

When it is anticipated that a mobile system will be moved between PDP cycles, the mobile system operator shall inform the HSG PDP coordinator that this move is anticipated. The HSG PDP coordinator will authorize the mobile system operator to either retain one set of PDP sample canisters with sufficient pressure to perform additional analyses, or obtain an additional canister set for the operator. Once the mobile system is operational at the new location, the PDP samples will be analyzed. Typically, the operator will know the certified values for the PDP samples at this time. Therefore, the operator will submit the PDP results to the HSG PDP coordinator as stated in the PDP Plan. In addition, the operator will include a data package consisting of:

(1) total ion chromatograms and instrument-produced quantification reports for all applicable calibration curves,

(2) total ion chromatograms for all PDP samples, and

(3) mass spectra or instrument-produced quantification reports for all PDP samples.

The HSG PDP coordinator will score the results and notify CBFO. A letter documenting continued approval or required corrective action(s) for the system at its new location will be issued to the appropriate Operations Office and to the operator by CBFO. The operator at the new location shall retain a copy of the letter to support the activities of the certification auditors. Sufficient instrument data should be retained to allow auditors to verify the date and time of analysis of the PDP samples at the new location. Once the analyses of the PDP samples are successfully completed, the sample canisters will be returned to the sample preparation contractor. In all cases the PDP sample canisters must be returned from the mobile system operator to the sample preparation contractor 60 days prior to the initiation of a new PDP cycle.

This between-cycle analysis of the PDP samples by a mobile system at a new location does not need to be completed prior to putting the system in service certifying waste as long as the same procedure for the analyses is used at the new location. Waste analyses can begin when all WAPrequired initial set-up activities are completed (e.g., calibration, QAO determinations). If corrective actions are identified as a result of the between-cycle PDP sample analyses, they should be implemented following identification of the issue and prior to further waste characterization at the new location. 